\section{HOTÉIS ECONÔMICOS NO BRASIL}

\section{José Celso Martineli}

RESUMO: As diferentes crises econômicas (uuc o P'aís vem at travessando confrontam-se com a necessidade crescente da locomoçäo a tral ralho ou passeio. de um número cada vé maior de pessoas yue circulam pelo território nacional scm op̧̧óes de hospedagem baratat ca a mesmo tempo que se apresentem conforto $\mathrm{c}$ un bom nivel na qualidade dos scrvicos prestados. Seguindo o excmple de out ros paíscs. o Brasil, yue até agora sempre destinou investimentos ao turismo de alto padräo vem sc preocupando com o descnvolvimento dos "hotéis Je basc". cuja neccssidade se torna cada vez. mais evidentc. a partir de estudos fuec comprovam sua eficiencia num mercado a ser explorado.

PALAVRAS-CHAVE: Hotelaria: Brasil: turismo: hotel cconomico

ABSTRACT: The diferent ecomomic criss that the commen use wh hese, facing with the increasing mumber of poople which are tratcling in the

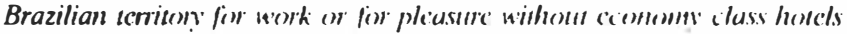

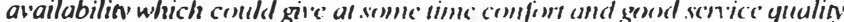

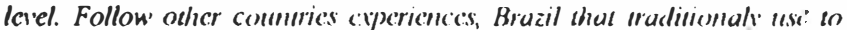
invest in the high level turisin stmicure, is non preoctupared to give incentives to develop econom! class hosels. hased on a stud that shenes the cfficicncy of this kind of hotcls int a marke't to be cuplened.

KEY WORDS: Hotel busincss: Bruzil: tourism: cconomen class hotch

\section{INTRODUÇÃO}

Até hoje os investimentos destinados aos meios de hospedagem no Brasil, foram, na sua maioria, direcionados a hotćis de alto padrāo. Pıuca

1 Bacharel em Relaçőes Públicas pela Universidade I sstadual de I ond rina. Paraná. Curso de Administraço de Restaurantes pela lichl Ilorclićrì de I ausannc. Suica Curso de Administracăo Hoteleira pelo centre Inuernational de Cilion Sivica Dre de

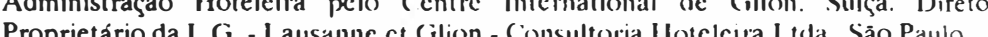
End para corresp: Rua llocoler Pillman. 175 - Givanja Julicla - 0471\%)-060 Săo Paulo End. para corr - SP - Brasil. atençāo $c$ incentivos for am dados a pequenos hotéis, que a exemplo de outros paises, também representam um mercado de grande utilização.

Começa a surgir uma preocupaçāo dos órgàos competentes do turismo no desenvolvimento dessa hotclaria de hase, que pode atender a demanda de um público bastante amplo no Brasil.

Até o final de 1992 a EMBRATUR - Instituto Brasilciro de Turismo, através do FUNGETUR - Fundo (icral de Turismo - estará empregando vinte milhões de dólares na chamada Hotelaria Ecomimica, at ravés de um projeto padrão que apresenta parâmetros de construçāo e investimento para hotéis de 50 a 80 apartamentos em todo o País

() desenvolvimento dos chamados hotéis economicos dentro da realidade brasileira é incvitável, na medida em que a incxisıĉncia desse meio de hospedagem poderá comprometer o crescimento do turismo como atividade econômica gerada para atcnder an necessidades do investidor e do turista, dentro da renda disponível no mercado.

\section{HOTÉS ECONOMICOS N() MUNDO}

Os hotéis econômicos tiveram inícion na década de 19)(0), nos Estados Unidos, principalmente próximo a rodovias e auto-estradas, onde viajantes de automóveis e caminhōes utilizavam-se de scus scviços. Surgiram entāo as primeiras redes, como por exemplo a Holiday Inn, introduzindo toda uma sistematização e padronizaçāo de trabalho.

A racionalização na prestaçāo dos serviços dos hotéis econômicos, sem perder a qualidade e o conforto no atendimento ao hóspede, são suas principais características que determinam um preço acessível aos clientes que buscam comodidade, eficiência c rapidez.

A idéia foi se espalhando e crescendo por outros países do mundo, inclusive na Europa, onde um significativo contingente de turistas, homens de negócios (comerciantes), estudantes e alć mesmo pessoas da terceira idade buscam os hotéis econômicos como principal meio de hospedagem.

As principais características dos hotéis ceonômicos sāo as seguin-

a) racionalidade: padronizaçào e sistcmat izaçào dos serviços implicando numa reduçāo dos custos de operaçía c administraçáa:

b) mäo-de-obra: facilidade de adaptação c aproveitamento da māo-de-obra pouco especializada disponivel no mercado brasileiro; o treinamento torna-se peça fundamental na adequaçāo dos 
funcionários ao hotcl, o qual apresenta um menor nível de exigência em termos de qualificação;

c) planejamento físico: melhor aproveitamento do espaço disponível, objetivando a maximização da funcionalidade c implicando num volume de investimento viável às condiçôes cconômicas do Brasil;

d) público: é cada vez maior o número de brasilciros que não conseguem viajar sem utilizar a "para hospedagem" (casas de aluguel, por exemplo), devido ao achatamento dos rendimentos; com a criação e desenvolvimento dos hotéis econômicos, uma nova forma de turismo poderá "abrir as portas" a esse público consumidor de classe média, que não possui opçōes de turismo econômicas c viáveis;

e) profissionalismo: é comum a identificação do hotel cconômico com a empresa familiar; tal conccito não deverá per maneccr, pois o principal objetivo e característica desse tipo de cmprecndimento é a utilização racional dos recursos disponíveis (mão-de-obra. capital, tecnologia etc.), combinado-os de mancira profissional e menos subjetiva possível, visando um alto atendimento qualitativo do hóspede;

f) modalidade: um sistema de administração de fácil operação de empresas hoteleiras, apresentando um atendimento de qualidade ao cliente.

O sistema serve como base para o desenvolvimento de projetos específicos, como por exemplo, o hotel para estudante. ${ }^{2}$

\section{HOTÉIS ECONOMICOS NO BRASIL: O Microtel}

Após vários anos de pesquisas e trabalhos desenvolvidos na área hoteleira em todo o Brasil, criou-se um produto na linha do hotel econômico, chamado Microtel - um sistema hotelciro voltado exclusivamente à realidade brasileira. Nesse projeto as prcocupaçōcs básicas são as seguintes:

a) o proprietário, normalmente, não é do ramo;

b) o administrador em geral não conhece profundamente a hotclaria;

c) carência de mão-dc-obra cspecializada;

2 Num hotel desse tipo, o estudante encontrará um local agradável. onde poderá morar com segurança, higiene, privacidade, conforı e facilidades de um se tviço hoteleiro, sem gastar muito. O preço será compativel com as possibilidades dos jovens de classe média brasileira, obrigados. muitas vezes. a utilizar pensỏes e repúllicas. onde os fatores mencionados săo de difícil concretizaçăo. d) as condiçōes financeiras do micro-cmpresário, viajantc, reppresentante de venda e do turismo da classe média brasilcira;

e) a localização - pode ser construído perto de um grande centro, ou de uma cidade de vinte mil habitantes:

f) os investimentos - um conjunto de dez pessoas podem tranquilamente construir um hotcl desse porte;

g) sistema de apartamentos "standart", ou scja, todos iguais, facilitanto a operação e manutençāo dos quartos c a comcrcializaçào, que será feita através de unidades habilacinais c não por camas. Excmplo: para uma ou duas pessoas no mesmo quarto, o preço scrá o mésmo.

Constitui, assim, uma categoria de hospedagem que unc qualidade, conforto e diárias acessíveis, graças à eliminaçäio do supérfluo, além de uma estrutura administrativa racional e eficientc. Um dos aspectos mais interessantes desse projeto é que cada unidade Microtcl possuirá uma recepção-kiosk, onde se fará o "check in" c "check out". Ncla os hóspedes encontrarāo, também, uma cspécie de "drugstore" com produtos descartáveis e de uso imediato para atender às suas necessidades.

O investimento global desse tipo de hotel econômico é estimado em torno de um milhão de dólares, com um terreno de áréa mínima de 2600$) \mathrm{m}^{2}$. Em seus $1600 \mathrm{~m}^{2}$ de área construída, possuirá apcnas dois pavimentos (dispensando elevadores), com 76 módulos padronizados c estacionamento externo. Dependendo da regiāo c localizaçào, a diária scrá aproximadamente de dez a vinte dólares, e o retorno do capital investido será de seis a dez anos.

\section{CONSIDERAÇÕES FINAIS}

Para o desenvolvimento do turismo como uma das principais atividades econômicas do País, é neccssária viabilizaçán éconômica dos meios de hospedagem, tanto para o público usuário como para o investidor.

Nesse processo torna-sc cada ve mais cvidente a criação de projetos de hotéis econônicos que, sem perder a qualidade, operem com redução de custos c possam scr adaptados a qualquer localidade. Representam, assim, um importante meio de desenvolvimento para regiōes com pouca infra-estrutura geral e turística, a screm explorados, mas voltados à realidade brasileira e suprindo as necessidades de todos os agentes de mercado. 


\section{BIBLIOGRAFLA}

L.A MARMITE. 1992. I ausannc. n.82. mars. (Jornal da I cole llotclićrè de l ausanne) LE JOURNAL. 1992. Glion, n.6\%) janvier. (Jornal bimestral do (.ent re International de Glion)

EMBRATUR - Instituto Brasileiro de Turismo. 19)2. fimtes de financiamento para o apoio a projetos turlsticos. Rio de Janciro: I:mbratur.

LUNDBERG. D. E. 1985. The hotel and restamam business. $3 \mathrm{~cd}$. 